\title{
Flotation froth feature analysis using computer vision technology
}

\author{
Artem Romachev ${ }^{1 *}$, Valentin Kuznetsov ${ }^{1}$, Egor Ivanov ${ }^{1}$ and Benndorf Jörg ${ }^{2}$ \\ ${ }^{1}$ Saint-Petersburg Mining University, Mineral Processing Department, 199106 Saint-Petersburg, \\ Russian Federation \\ ${ }^{2}$ TU Bergakademie Freiberg, Institute for Mine Surveying and Geodesy, 09599 Freiberg, Germany
}

\begin{abstract}
Annotation. The possibility of machine vision application in the field of flotation efficiency evaluation was studied. Algorithm for froth image analysis was developed with aim of obtaining bubble's size distribution. Algorithm consists of two parts: image processing and object detection. Algorithm's work was verified on the sulfide flotation froth. As result, mathematical correlations for air flow rate, mean bubble diameter and surface area bubble flux were established.
\end{abstract}

\section{Introduction}

Flotation process is the most complicated in the terms of automatization and maintenance. That is due to the difficulty of inherent and numerical process properties. Each parameter can be defined with high precision as the result of production experiments or with special equipment, but in case of the continuous process this seems impossible without interrupting sub-processes taking place in the flotation cell. From the visual control perspective, the simplest way to analyze the flotation efficiency is to evaluate the froth parameters. This fact is confirmed by the vast amount of works in the past century, that were dedicated to the study of correlation between the froth phase state and the efficiency of the flotation efficiency. It should be noticed that in these studies the fundamental role of the bubbles size distribution in the process of mineral transfer to the froth was asserted. In the work [1] it is also stated that the problem of obtaining the right size bubbles issue significant issue for the researchers. Also known that the degree of froth mineralization is directly proportional to the froth depth, volumetric concentration of the floatable components of the pulp and the form of the solid particles [2]. So that, monitoring and control of the bubbles production with the aim of achieving the optimal size distribution is one the most important technological problems.

The issue of bubble size measurement was studied for nearly a decade, and different measurement methods were proposed. Review of that methods can be found in [4-6]. Among the available methods for explicitly defining the bubble size distributions, visual (photographic) methods based on digital image processing and analysis have long been used to study the effects on flotation $[2-3 ; 6,7-14,17]$. These methods have proven to be the most reliable in case of bubble sizes measuring in various industrial and experimental applications. According to $[3,16]$, an inclined viewing camera of the type proposed by [18] reduces the probability of bubbles overlapping each other on the image, thereby reducing the probability

*Corresponding author: romashev_ao@pers.spmi.ru 
of bubbles miscalculation. Usually, a visual determination is made by sampling methods using a device (containing a tube) to collect the bubbles and then direct the bubbles to the camera (bubble viewer), which is usually located at the top of the camera. But the use of such methods requires direct intervention in the flotation cell and can disturb the process dynamics and produce distorted results. Also question of analyzing the obtained images remains open.

One of the first proposed and successfully implemented solutions in this field is the Outotec ${ }^{\circledR}$ Frothsense sensor system [18]. This implementation is designed to monitor the froth surface in real time and measure the following characteristics:

- the direction and speed of the froth current;

- bubble size distribution;

- froth stability;

- froth color (RGB and CIE-LAB);

- failure detection: no overflow at the front end.

To carry out monitoring, several cameras are installed on the flotation machine, from which images are processed by the Outotec FrothSense ${ }^{\circledR}$ analysis server, which works the image recognition algorithms and sends error signals to the control system used on the plant [18]. Despite the efficiency of this development, its price, and the need to install a specialized aperture narrow the range of its applications [18].

Modern development of IT technologies and machine vision allows the development of systems that significantly simplify the task. In this paper, one of the possible solutions based on the machine vision technology is considered.

\section{Materials and methods}

For following study technological samples of sulfide gold-bearing ores were prepared. These samples belong to sulfide, quartz-pyrite-arsenopyrite ore type. These ores are products of hydrothermal changes in volcanosedimentary rocks: sandstones, siltstones, and acidic effusions. Sulfides are represented by separate grains and aggregates with different ratios of pyrite and arsenopyrite. Gold, as the most valuable component in the ore, is associated with sulfides. The average component content in the samples varies between $1.4 \mathrm{~g} / \mathrm{t}$ and $6.2 \mathrm{~g} / \mathrm{t}$.

Flotation test were conducted in the pheumomechnical flotation machine, with flotation cell volume of $0.2 \mathrm{~L}$. Experimental conditions are based on the studies of the sulphide flotation [19,20]. Flotation was carried out with using potassium butyl xanthate in concentration of $120 \mathrm{~g} / \mathrm{t}$ as the collector and solution of dextrin as a depressant in concentration of $80 \mathrm{~g} / \mathrm{t}$. As frother the reagent Flotanol VS-1M was used in concentration of $50 \mathrm{~g} / \mathrm{t}$. This reagent is a mixture of high alcoholos and various aromatic compounds. The $\mathrm{pH}$ of the process was maintained at level of 9.0-9.5. The depth of the froth was maintained at $0.5 \mathrm{~cm}$. During the test air flow rate was varied in range of $5-30 \mathrm{~cm}^{3} / \mathrm{s}$.

Design of the test setup is represented in the figure 1.

To improve the quality of the bubbles geometric dimensions measurement, the flotation machine camera was illuminated from a scattered light source. A shooting camera was installed in close proximity to the flotation cell. A fragment from the central area was taken for analysis. Shooting was carried out at defined points in time (at the end of the froth removal cycle) and the final result was taken as the average diameter value obtained after processing the images. 


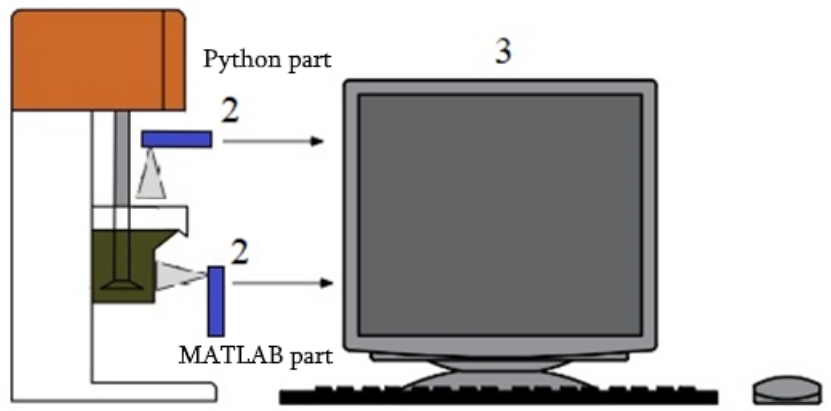

Fig. 1. Test setup for the flotation process analysis design. 1 - Flotation machine, 2 - Camera, 3 - PC Hardware

Following results are based on the several assumptions. First is that deformation of the bubble in the first moment of entering the froth is minimal and with descent froth removal, the error could be minimized. Second is that obtained values of the surface are bubble flux can be applied only for the flotation models based on the plug-flow model (i.e. column flotation modeling). This assumption based on the fact of low contribution of the substantial centripetal forces in the air dispersion value.

\section{Results and discussion}

In purpose of automatic bubble size's measurement algorith for image analysis was developed using Mathlab and Python enviornment. So that essence of the algorithm reduces to the rondure marking on the images (fig.2).

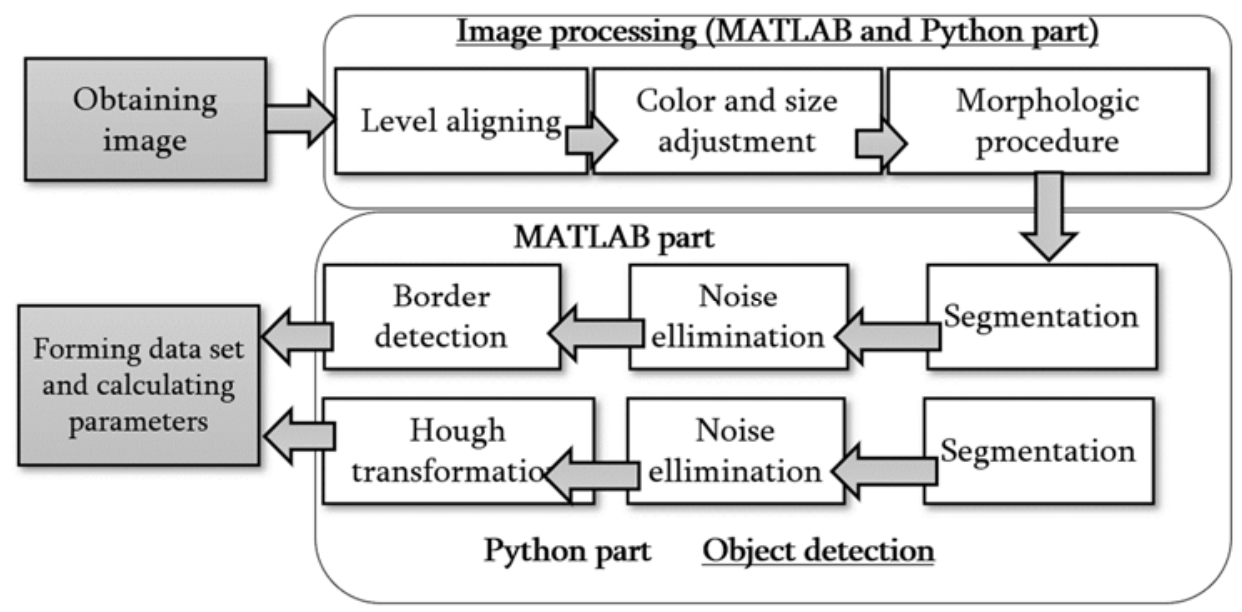

Fig. 2. Bubble detection algorithm

For that purpose, a number of filters were applied to the original image in aim to smooth out and suppress noise. That was achieved by blurring the image with the Gauss filter.

Before the direct image processing, the image is resized to reduce running time and converted to grey shades. Further it is necessary to increase contrast of colors of a background and bubbles. This is achieved by segmentation, i.e. splitting the image into many areas - areas of the background and areas of the bubbles themselves. One way to segment an image is threshold image processing or image binaryzation. The main parameter of such transformation is the threshold rate - the comparison value for compared brightness of each pixel. According to the results of the comparison, the pixel is assigned a value of 0 or 1 and, 
as a result, it is colored in black or white. The threshold value was determined manually and was taken based on the most precise segmentation of bubbles and background (fig 3.).

After segmentation, the image can be applied for bubble detection. To do this, using special module in Phyton software enviornment used the Huff Transformation, which is one of the most common methods in the field of geometric elements detecting, in particular for round figures. The application of the Huff transformation in images processing with a large number of bubbles gives very inaccurate results. In addition, the original image shows that the background color varies in different parts, making it difficult to determine the binaryization threshold value. Therefore, it was decided to divide the image into several areas and then to combine values of the obtained circles radii into a single data array.
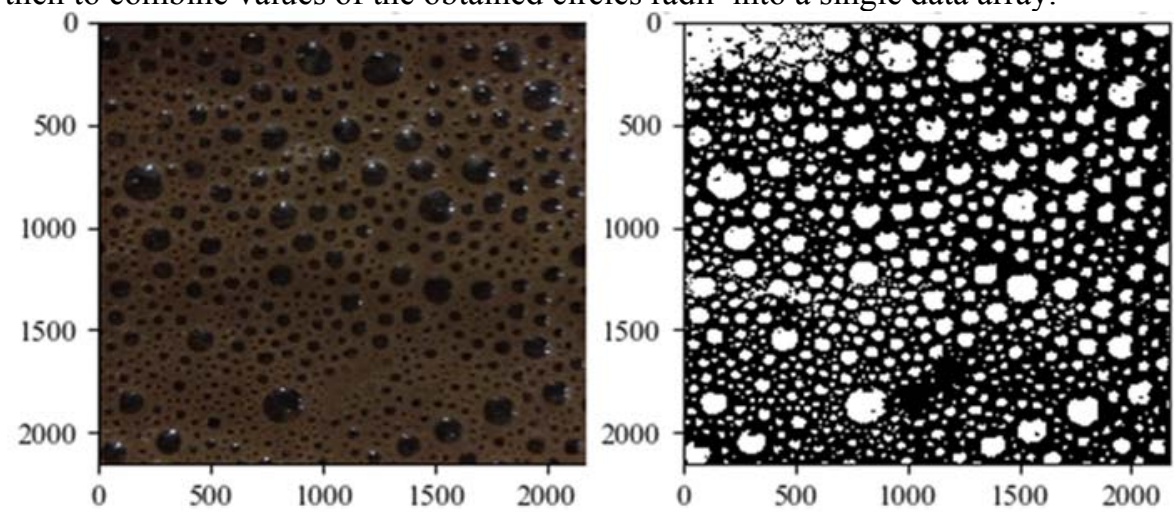

Fig. 3. Image processing

In MathLab software enviornment boundaries were determined by the Canny Edge Detector method, as compared to other well-known methods (Sobel, Roberts, Pruitt, etc.) the method has significant advantages:

- provides good edge detection;

- provides a clear response;

- provides a good localization.

For elimination of false detectable objects the filling of closed areas on the image and operations of mathematical morphology was used. The proposed approach allows to determinate the number and size of bubbles in the area under consideration, but there are also a number of difficulties, in particular, detection errors when the bubbles are superimposed on each other is possible. However, when calculating the relative velocity of gas, these errors do not make a significant error and can be accepted as an assumption. The results of boundary definition as well as bubble distribution are shown in Figure 4.
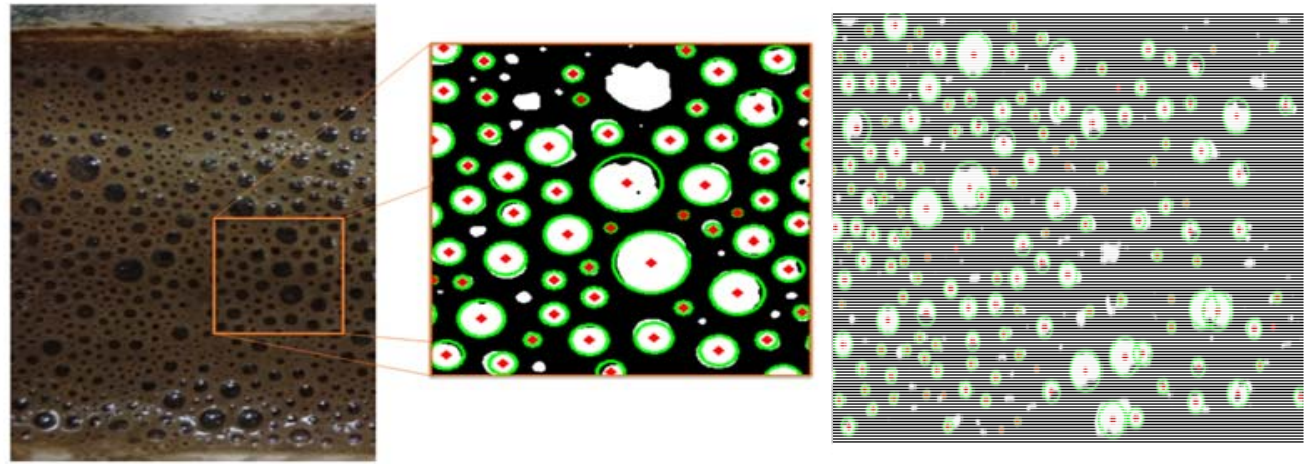

Fig. 4. - Results of the algoritm implementation 
Obtained results of the bubble size measurement were used for calculating the surface area bubble flux $\left(\mathrm{S}_{\mathrm{b}}\right)$. This parameter was developed for mathematical representation of the gas dispersion in the flotation cell as the parth of the AMIRA P9 Project. The surface area bubble flux is widely used in the first order flotation models to define the flotation rate constant.

The $\mathrm{S}_{\mathrm{b}}$ parameter can be calculated by the following equation [3]:

$$
S_{b}=\left(6 \cdot Q_{A} \cdot \sum_{i=1}^{n} d_{i}^{2}\right) /\left(A \cdot \sum_{i=1}^{n} d_{i}^{3}\right) \cdot, \mathrm{m}^{2} \quad \mathrm{~s} / \mathrm{m}^{2}
$$

where: $Q_{\mathrm{A}}$ - air flow rate, $\mathrm{m}^{3} / \mathrm{s} ; d_{i}-$ individual bubble diameter, sm; $A$ - cross-sectional area of the flotation cell, $\mathrm{m}^{2}$.

Surface area bubble flux is the complex characteristic of the air dispergation in the flotation cell, as the mean bubble diameter, that deeply correlates as with equipment characteristics and physical chemical properties of the ore. However, in the first stage evaluation of the process efficiency for increasing particle-bubble contact the $S_{b}$ parameter must be as high as possible for the lowest value of the mean bubble diameter.

However, there are some limitations for process characterization by this parameter. This parameter is designed for measuring bubbles in the flotation cell, not in the froth. So, there could be calculation errors associated with bubble deformation due to the froth destruction and bubble coalescence, that must be taken in the consideration.

Experimental results of the bubble size measurement and surface are bubble flux due to te air flow variation presented in the table 1 . The graphic interpretation of the obtained results is presented on the figure 5 .

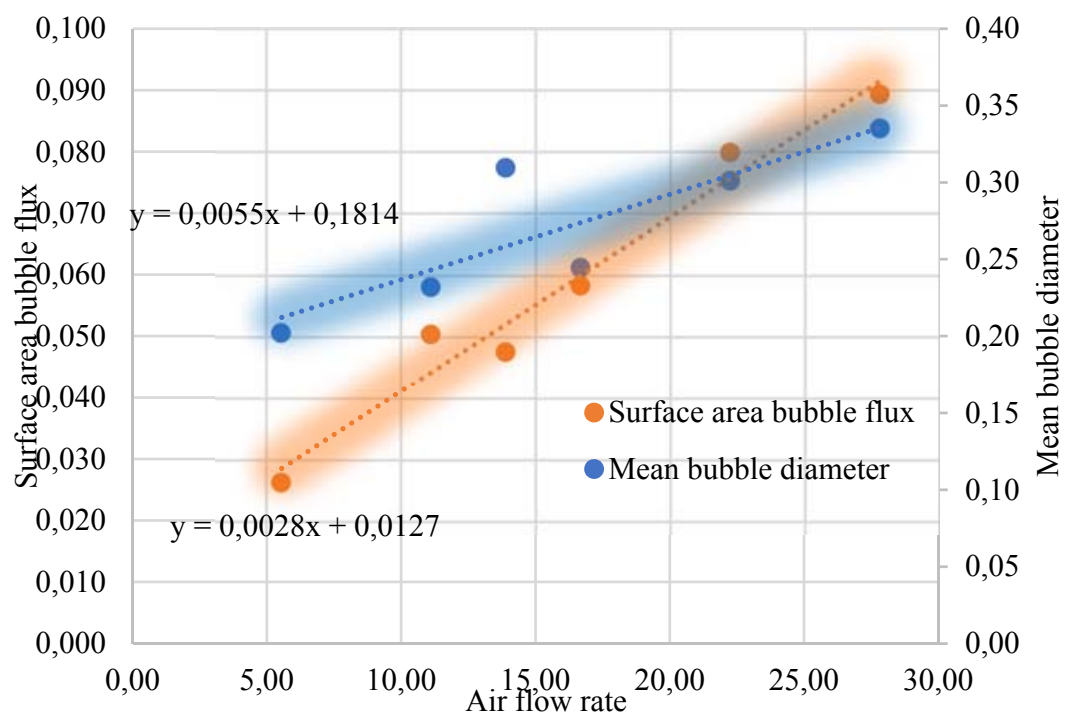

Fig. 5. Correlation between the surface area bubble flux, mean bubble diameter and the air flow rate. 
Table 1. Experimental results of the bubble size measurment

\begin{tabular}{|c|c|c|c|}
\hline № & Air flow rate, $\mathrm{cm}^{3} / \mathrm{s}$ & Mean bubble diameter, $\mathrm{cm}$ & $\mathrm{Sb}, \mathrm{m}^{2} \mathrm{~s} / \mathrm{m}^{2}$ \\
\hline 1 & 5.56 & 0.20 & 0.026 \\
\hline 2 & 11.11 & 0.23 & 0.050 \\
\hline 3 & 13.89 & 0.31 & 0.048 \\
\hline 4 & 16.67 & 0.25 & 0.058 \\
\hline 5 & 22.22 & 0.30 & 0.080 \\
\hline 6 & 27.78 & 0.34 & 0.089 \\
\hline
\end{tabular}

As the result of the measurement mathematical correlations between studied parameters were obtained:

$$
\left\{\begin{array}{l}
S_{b}=0.0028 * Q_{A}+0.0127 \\
d_{m}=0.0055 * Q_{A}+0.1814
\end{array}\right.
$$

Taking into the consideration the fact that the stability of the bubble is increasing with mean bubble size decreasing, the optimal values of the $S_{b}$ and $d_{m}$ should be defined from the further analysis of physical-chemical properties of the ore and what bubble size and speed of the current in the flotation cell will be acceptable for the increasing probability of the particle and bubble contact in the cell .

The work is carried out with financial support of Ministry of Education and Science of Russian Federation according to grant program "Research and development in priority areas of development of Russia's scientific and technical complex for $2014-2020$ ”, the project № 05.616.21.0127 (RFMEFI61620X0127).

\section{References}

1. A. M. Gaudin. Flotation. - McGraw-Hill (1957)

2. M. A. Seger, C. Oliveira, R. T. Rodrigues. Minerals Engineering. I. 142, 105936. https://doi.org/10.1016/j.mineng.2019.105936 (2019)

3. T.N. Alexandrova, A.O. Romashev, V.V. Kuznetsov. Obogashchenie Rud, 2, 9-14. (2020).

4. F. Chen, C.O. Gomez, J.A. Finch, Miner. Eng. 14 (4), 427-432. https://doi.org/10.1016/S0892-6875(01)00023-1. (2001)

5. R.T. Rodrigues, J. Rubio. Miner. Eng. 16, 757-765. https://doi.org/10.1016/S08926875(03)00181-X. (2003)

6. R. Grau, K. Heiskanen. Miner. Eng. 15 (7), 507-513. https://doi.org/10.1016/S08926875(02)00074-2. (2003)

7. R.A. Grau, K. Heiskanen, Miner. Eng. 16, 1081-1089. https://doi.org/10.1016/j.mineng.2003.06.007. (2003)

8. J.R. Hernandez-Aguilar, R.G. Coleman, C.O. Gomez, J.A. Finch, Miner. Eng. 17 (1), 53-61. https://doi.org/10.1016/j.mineng.2003.09.011. (2003)

9. J.R. Hernandez-Aguilar, C.O. Gomez, J.A. Finch. In: Nesset, J.E. (Ed.), Proceedings of the 34th Annual Meeting of the Canadian Mineral Processors, 389-402 (2002)

10. R.T. Rodrigues, J. Rubio, 2003. Miner. Eng. 16, 757-765. https://doi.org/10.1016/S08926875(03)00181-X. (2003)

11. S. Ata, G.J. Jameson, Int. J. Miner. Process. 76, 123-139. https://doi.org/10.1016/j.minpro.2004.12.007. (2003)

12. A. Elbendary, T. N. Aleksandrova. Apatite-Nepheline Deposits Journal of Materials Research and Technology, 8 (6), 5080-5090. https://doi.org/10.1016/j.jmrt.2019.08.027 (2019)

13. T.N. Aleksandrova, N.V. Nikolaeva, V.V. Lvov, A.O. Romashev, Obogashchenie Rud, 2, 813. https://doi.org/10.17580/or.2019.02.02 (2019)

14. L. Vinnett, J. Yianatos, M. Alvarez, Miner. Eng. 57, 12-15. https://doi.org/10.1016/j.mineng.2013.12.006. (2014) 
15. M. Maldonado, A. Desbiens, É. Poulin, R. Del Villar, A. Riquelme, Int. J. Min. Process. 141, 27-33. https://doi.org/10.1016/j.minpro.2015.06.003. (2015)

16. R.A. Grau, An investigation of the effect of physical and chemical variables on bubble generation and coalescence in laboratory scale flotation cells. Dr. Sci. Dissertation, Department of Materials Science and Engineering - Helsinki University of Technology, Finland. 78. (2006)

17. N. Nikolaeva, T. Aleksandrova, D. Semenikhin, International Multidisciplinary Scientific GeoConference Surveying Geology and Mining Ecology Management, SGEM, 17 (11), 1067-1072. https://doi.org/10.1016/10.5593/sgem2017/11/S04.136 (2017)

18. Outotec FrothSense ${ }^{\mathrm{TM}}$, https://www.outotec.ru/globalassets/ru/brochures/outotecsensornaya-sistema-frothsense-pdf (last visited Aug. 4, 2020)

19. T.N. Aleksandrova, I.V. Talovina, A.M. Duryagina, Gold-sulphide deposits of the Russian Arctic zone: Mineralogical features and prospects of ore benefication Chemie der Erde. https://doi.org/10.1016/j.chemer.2019.04.006 (2019)

20. T.N. Aleksandrova, G. Heide, A.V. Afanasova, Journal of Mining Institute, 235, 30-37. https://doi.org/10.31897/PMI.2019.1.30(2019) 